\title{
A VOZ E A TRAVESSIA DA RUÍNA: CASO ROBERTO PIVA OU DO SEXUAL AO TEXTUAL
}

\author{
Evandro de Sousa (UFSC) ${ }^{1}$
}

\begin{abstract}
Resumo: Este artigo é a proposta de abordagem da relação entre poesia (entendida no lato sensu do termo poética) e a paranoia, tomando como base a relação com a voz. O objeto eleito para esta intervenção é a leitura do poeta paulista Roberto Piva do poema Antínoo \& Adriano, através da qual se visa demonstrar a formulação das ruínas à representação (a falta de garantias na escrita) e produção de uma subjetivação forjada no nível entonacional que vincula sujeito e corpo para efetuar então a passagem do campo da experiência da fantasia (notadamente o sexual) para o território da letra (o textual).
\end{abstract}

Palavras-chave: voz; análise do discurso; psicanálise; entoação.

\section{Antínoo \& Adriano}

Esta é a zona batida pelos afogados

Está é a velocidade máxima de quem submerge

aqui as romãs romanas não crescerão mais

\& duas águias de névoa orvalhando sandálias

adolescentes na grama de primavera escrevem

a palavra remember

o doce Antínoo com seu arco carregando

corações maduros na aljava na fenda-essência

da história

os semáforos do tempo acendem seu sinal

verde por cima de sua

longa cabeleira

este doce garoto

partiu o coração do imperador

o Império adorando um deus adolescente afogado no Nilo

sem esperar a manhã egípcia chegar

Adriano chorou o resto de sua

vida na villa ao sul de Roma

as paredes rachavam pelas tardes

deixando entrar as lembranças

houve um tempo nas montanhas da

Bítinia quando as caçadas se prolongavam

até a hora do amor

o vinho Falerno aderindo aos estômagos

vazios enquanto olhares se

cruzavam sobre o javali assado rodeado

de frutas

1 Doutorando em Teoria Literária, pelo Programa de Pós-Graduação em Literatura da Universidade Federal de Santa Catarina, sob orientação do prof. Dr. Pedro de Sousa. E-mail: evbsousa@gmail.com 


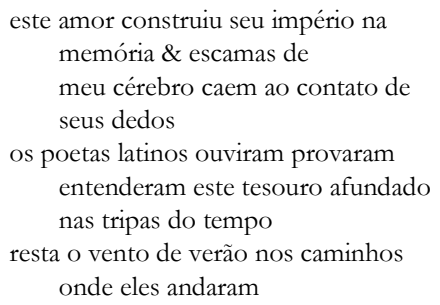

\title{
Exegese
}

Jacques Derrida, em seu opúsculo de 1987, intitulado Khôra, propõe uma cena de leitura cujo aporte latente é a caverna de Platão. Nesta direção, efetuo o contraste com o que, a partir também de Platão, Jacques Lacan propõe. Resta-nos do que ele disse, na Capela de Sainte-Anne, em 06 de janeiro de 1972, e que nos escreve, a partir dele, Jacques-Alain Miller:

\begin{abstract}
[...] Suponham que a caverna de Platão seja estas paredes em que minha voz se faz ouvir. É patente que as paredes, isso me faz gozar. E é nisso que todos vocês gozam, cada um de vocês, por participação. Ver-me falando com as paredes é algo que não pode deixá-los indiferentes. E pensem bem, suponham que Platão tenha sido estruturalista: ele teria percebido o que se dá realmente com a caverna, ou seja, que, sem dúvida, foi nela que nasceu a linguagem.

É preciso inverter a coisa. Por muito tempo o homem soltava vagidos como qualquer dos bichinhos que piavam para beber o leite materno, mas ele precisava de algum tempo para perceber que é capaz de fazer uma coisa que, é claro, ouve desde longa data, porque no balbucio, no resmungo, tudo se produz. Para escolher, ele teve de perceber que os cás soavam melhor vindos do fundo, do fundo da caverna, e que os pês e os bês, isso brotava melhor na entrada, era lá que ele ouvia a ressonância deles (LACAN, 2011, p. 82).
\end{abstract}

Lacan desloca a caverna platônica e interpreta o mito, evoca para tanto a dimensão do aparelho fonador: é a garganta, os órgãos ativos e passivos da articulação que compõem, nesta hipótese psicolinguística, a estruturação da caverna. Assim é que, em termos fonéticos, as bilabiais [p] e [b], bem como a velar $[\mathrm{k}]$, marcam na cavidade oral o espaço de sua constituição. O interessante é que Lacan possibilita o deslocamento do traço, o soar melhor nos lábios ou próximo ao véu palatino é que constitui a dimensão física do significante (ver: Seara, Nunes e Lazzarotto-Volcão, 2011).

Tendo isto em vista, a dimensão de uma voz, de um eco na caverna, é que evoco, para além do escrito (e publicado) em Coxas, de 1979, republicado pela editora Globo em 2006, sob o título de Mala na mão \& asas pretas, a gravação em áudio, realizada também para o último volume das obras 
completas de Piva, Estranhos sinais de Saturno (2008), intitulada Nama coracibus tutela Mercuriis (2008). Para tanto evoco a segunda faixa do compact-disc, em que o poeta realiza seu poema intitulado Antinoo \& Adriano.

Diferenças evidentes entre o texto escrito e sua performance é sua duração: na página o texto se compõe como simultâneo, todos os versos aparecem num mesmo momento, eu posso ver o todo, enquanto na sua realização (leitura) apenas a dimensão da sucessividade me é dada ao acesso. É preciso esperar que o tempo trabalhe, uma vez que é como música que o poema se realiza. Ademais, o poema tem a breve duração de $1 \mathrm{~h} 30 \mathrm{~min}$, sendo que em sua realização são obliteradas (recalcadas?) as epígrafes que aparecem no escrito:

[...] L'énigme du labyrinthe est celle-ci: comment descendre jusqu'à Dionysos sans perdre la conaissance du chemin? A Kremer-Marietti, L'bomme et ses labyrinths.

[...] The rain outside was cold in Hadrian's soul. Fernando Pessoa, "Antinous" (PIVA, 2005, p. 84).

Ora, dito isto de outra forma, a questão do trabalho poético é atravessada por sua lalação, seu campo de ressonância, uma vez que integrada à letra, a ruína da voz é tomada pelo advento do simbólico. A caverna de Platão, na sua versão moderna, só pode ser comparada (após esta passagem) às "estruturas espacializadas" de Kafka, o que na leitura realizada por Guattari e Deleuze se aproxima desta retomada da questão, em termos de literatura, no que nela reside de significante:

[...] Como entrar na obra de Kafka? Trata-se de um rizoma, de uma toca. O castelo tem "entradas múltiplas", cujas leis de uso e de distribuição não são bem conhecidas. O hotel da América tem inúmeras portas, principais e auxiliares, vigiadas por outro tanto de porteiros, e mesmo entradas e saídas sem portas. Contudo, parece que a Toca, na novela com esse nome, tem apenas uma entrada; quando muito, o animal pensa na possibilidade de uma segunda entrada que teria apenas por função a vigilância. Trata-se, no entanto, de uma armadilha, do animal e do próprio Kafka; toda a descrição da toca é feita para enganar o inimigo. Entraremos então por qualquer extremidade, nenhuma vale mais que a outra, nenhuma entrada é privilegiada, mesmo se for quase um beco sem saída, uma estreita passagem, um sifão, etc. procuraremos apenas com os quais outros pontos se conecta aquele pelo qual se entra, por quais cruzamentos e galerias se passa para conectar dois pontos, qual é o mapa do rizoma, e como ele se modifica se entrássemos por outro ponto. O principio das entradas múltiplas impede somente a introdução do inimigo, o Significante, e as tentativas para interpretar uma obra que na verdade se propõe apenas à experimentação (1977, p. 7). 
Inocência ou ingenuidade da dupla de pensadores, uma vez que ao salientar a experiência, esquecem-se do controle da escrita. Um romance de Kafka, por mais que impossibilite a interpretação, pode (e consequentemente vai) cair nela. O romance não é desmontável, sua sequência lógica dá a direção dos efeitos; por mais que neste quebra-cabeça faltem peças, a imagem que forma um todo não é totalmente destituída. Isto ainda, tendo em mente que Deleuze e Guattari evocam certa topologia da obra de Kafka: ela se constrói como imagem a partir do texto, logo, consequência lógica, o inimigo que queria ser evitado, o significante, é que põe o texto para funcionar e o engendra, para usar um termo também caro a Deleuze, sua lógica de sentido.

Diante do romance, a entrada privilegiada são os olhos, da imagem da letra à imagem que se forma pela combinação de letras e que é evocada no imaginário por força da imaginação. Em Deleuze e Guattari, Kafka é imajado, isto é, capturado pelas imagens que evoca. No caso do áudio, da literatura oral, a entrada privilegiada é outra. A voz que ressoa e parte de uma caverna entra noutra: da cavidade oral (e nasal) para a cavidade auditiva. A imagem não é prioridade, mas a sensação tomada no corpo, enquanto corpo, resquício de um corpo e de sua materialidade. Aqui nos colocamos na dimensão da experiência babélica da linguagem então pode sentida, no áudio, reitero, estamos às voltas com a alíngua.

Se de acordo com o que nos avalizaria o psiquiatra de Un arte de hacer ruinas, é preciso então, no caso de Piva, ver o que acontece após a entrada do "chivo vivo". O movimento anacrônico do texto, mas que se impõe em um indecindível que cabe perguntar, ainda que se mantenha sem resposta, o que aparece primeiro: o poema como texto ou como performance, qual é sua realização?

Porém, se é na ruína da língua franca, comum, utilitária e comunicadora que insiro este bode dionísico, o chivo em ruínas de Ponte, é na sua inviabilidade. A língua, pós-Babel, anoriginal, é retomada no seu grau zero: balbucio, lalação, alíngua. Assim é que é possível o deslizamento e a retomada da ruína do sentido. Exemplifico: o título do livro, em letra, é Coxas Sex fiction \& delírios, o que implica no glissade ao ouvido que impõe a basculação entre Sex fiction/Satisfaction, o que faz com que todo sentido possível seja um sentido de gozo do sujeito, a ficção desliza para o campo do sexual onde se visa a um tipo de satisfação.

O chivo de Ponte ainda pode ser tomado na sua dimensão trágica, isto é, nietzschiana, uma vez que n'O nascimento da tragédia, Nietzsche nos lembra que:

[...] Apolo não podia viver sem Dionísio! O "titânico" e o "bárbaro" eram, no fim de contas, precisamente uma necessidade tal como o apolíneo! E agora imaginemos como esse mundo construído sobre a aparência e o comedimento, e artificialmente represado, irrompeu o tom extático do festejo dionisíaco em 
sonâncias mágicas cada vez mais fascinantes, como nestas o todo desmesurado da natureza em prazer, dor e conhecimento, até o grito estridente, devia tornar-se sonoro; imaginemos o que podia significar esse demoníaco cantar do povo em face dos artistas salmodiantes de Apolo, com os fantasmais arpejos de harpa! As musas da "aparência" empalideciam diante de uma arte que em sua embriaguez falava a verdade, a sabedoria de Sileno a bradar "Ai deles! Ai deles!", contra os serenojoviais Olímpicos (2007, p. 38).

A intervenção do bode (expiador/espiador ${ }^{2}$ ), de Dionísio, é tomada por sua desmesura, isto é, por uma passagem pelo limite, pela borda, um transbordamento. No jogo das duas faces da moeda, entre Apolo e Dionísio, a moeda falsa só pode ser tomada em sua ruína, entre Dionísio e Apolo há um jogo de espelhos (fata Morgana, diria Umberto Eco), em que tudo se cindiria na dúplice transição entre luzes e trevas. Se a luz, por outro lado dá a ver, a treva dá a ouvir. Hipótese que leva à obliteração da visão para liberar a audição.

Tese orientalista, porque babélica e dionisíaca, que faz com que na Gramatologia, Derrida reafirme a posição do canto. O escrito, tanto quanto o poema, se tomado em sua estrutura material plástica e visual (o caractere com seu suporte), abrir-se-ia na circulação na esfera da máquina (o significante futurista), mas também da letra, na instância da letra (“[...]l'écriture, la lettre, l'inscription sensible ont toujours été considere par la tradition occidentale comme le corps et la matière extérieurs à l'esprit, au souffle, au verb et au logos" [DERRIDA, 1967, p. 52]). Isso também implica, na formação da instância institucional (canônica) da letra (e consequentemente da literatura), o lugar dúplice do escritor entre a imagem fetichizada e seu esvaziamento, isto é dizer da passagem (Khôra) do sens-place ao sans-place. A recusa dionisíaca do lugar do artista teria assim dois ecos: a impossibilidade da narrativa dado o empobrecimento narrativo, segundo os termos de Walter Benjamin nos anos 40, mas também a liberação da obra diante da imagem soberana do gênio que ela comportaria nos anos 60 , nos termos de Roland Barthes.

É preciso fazer notar que na dimensão da ruína, entre voz e fala, pouco avançamos. Assim, levanto mais uma hipótese que traduzo em termos benjaminianos: para os ouvidos, o poema entra em uma rua de mão única, ainda que entre na contramão. Explicar isto é permitir que a voz gravada e reproduzida (o $c d$ impõe a lógica da reprodutibilidade técnica do efêmero, do fugaz da voz, como um contraponto ao método taquigráfico que seria a ruína da experiência, dito de outra forma, aquilo que fica, resíduo, de um discurso).

\footnotetext{
${ }^{2}$ Espiador recoloca em cena um desdobramento da questão que em termos deleuzeanos poderia ser expressa como: o lugar do olhar em seu devir-animal, como uma solução de abertura a uma concepção do olhar fundador e objetivificante de Merleau-Ponty, que se torna com Deleuze, um olhar que já estranho na sua origem, indecifrável porque não tem necessidade de ser traduzido, olhar como puro gesto.
} 
'Ignorando por enquanto a "metade plástica da poesia", tomando aquilo que é da voz, e seu caminho, o Praat nos demonstra outra escritura deste efêmero que não reside no inteligível, mas como uma impressão do sensível (observe-se a gravura 1). Para além dos valores quantitativos ${ }^{3}$, a curva de pitch demostra de modo plástico (e consequentemente pedagógico) o ritmo, como se iluminasse/ilustrasse o vazio do rastro/ruína da voz. Porém, o dispositivo ainda pode ser mobilizado para um contra-argumento, o qual realizo como um parêntese e breve digressão.

${ }^{3}$ Como devido ao tamanho do período segmentado para análise, os valores numéricos da curva de pitch ficaram sobrepostas, para tanto os transcrevo aqui. Obteve-se para o título ("Antinoos \& Adriano"):

\begin{tabular}{|l|l|l|l|l|l|l|l|l|}
\hline 1 & 123 & 102 & 148 & 142 & 125 & 107 & 114 & F0 (7) \\
\hline 2 & $\mathrm{M}$ & $\mathrm{B}$ & $\mathrm{T}$ & $\mathrm{S}$ & $\mathrm{L}$ & $\mathrm{B}$ & $\mathrm{U}$ & Intsint (7) \\
\hline 3 & 123 & 123 & 146 & 146 & 123 & 103 & 113 & Predicted F0 (7) \\
\hline
\end{tabular}

Já para o primeiro verso ("esta é a zona batida pelos afogados"):

\begin{tabular}{|l|l|l|l|l|l|l|l|l|l|l|l|l|l|l|}
\hline 1 & 79 & 125 & 141 & 108 & 121 & 105 & 119 & 108 & 99 & 114 & 95 & 97 & 107 & F0 (13) \\
\hline 2 & $\mathrm{~B}$ & $\mathrm{H}$ & $\mathrm{H}$ & $\mathrm{L}$ & $\mathrm{U}$ & $\mathrm{D}$ & $\mathrm{U}$ & $\mathrm{D}$ & $\mathrm{D}$ & $\mathrm{U}$ & $\mathrm{L}$ & $\mathrm{S}$ & $\mathrm{U}$ & $\begin{array}{l}\text { Intsint } \\
(13)\end{array}$ \\
\hline 3 & 79 & 116 & 140 & 105 & 119 & 107 & 120 & 108 & Undefined & 114 & 95 & 95 & 110 & $\begin{array}{l}\text { F0 (13) } \\
\text { Fredicted }\end{array}$ \\
\hline
\end{tabular}




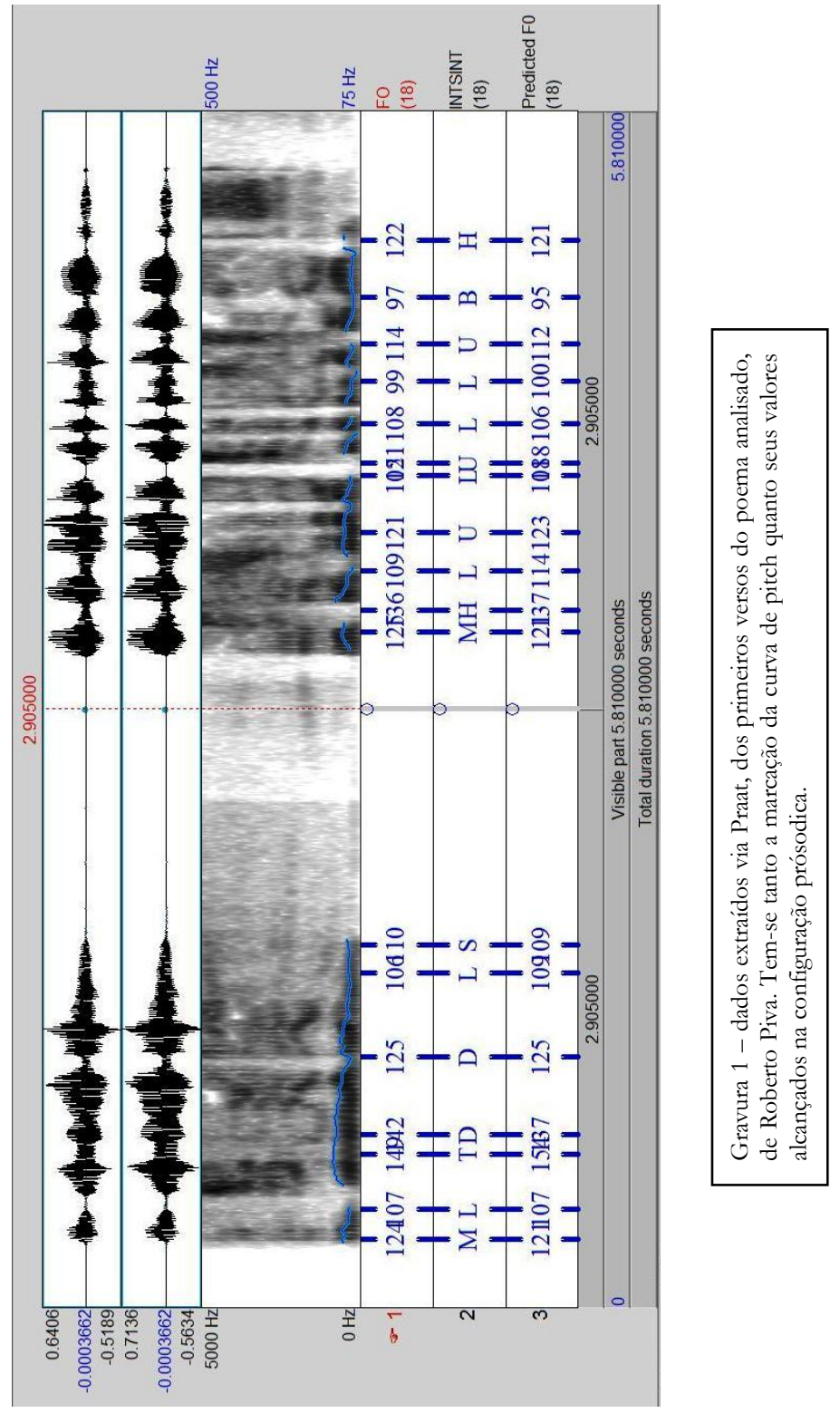


Tomado o argumento postulado por Giorgio Agamben, em $O$ fim do verso, diante do argumento (que poderia evocar como "quase" fenomenológico), o Praat demonstra que, na dimensão da voz (tomada enquanto realização material, física, ou sensível da fala), o conceito de enjambent, por se basear na letra (na visualidade gráfica/plástica do poema) e no nível de representação simbólica, rui. Ainda que Agamben retome o dístico de Valèry, não o executa no campo de uma dimensão radical, acabando por esquecer a lição de Paul Zumthor acerca dos textos medievos e o lugar da voz. $\mathrm{Na}$ eterna hesitação entre som e sentido, como o lê Agamben, há a aceitação tácita, latente, do valor da representação (a equivalência do que ocorre na letra deve ocorrer na fala). Há que se inserir aí a lição Jakobson-Saussuriana da cisão entre Langue e Parole, bem como a fundação de um discurso semiótico barthesiano. O corte vocal do verso não corresponde ao corte gráfico ou sua possibilidade. O trabalho no âmbito do som é, como reitera Lévi-Strauss, no âmbito do escrever da partitura, do qual a letra não demanda controle (ou ordem discursiva), mas está aberta à interpretação dada na realização. Temos então, como possibilidade, a ruína da letra (e do jogo ou acordo representativo entre as palavras e as coisas) para liberar o campo dos efeitos, suspensão da transcendência e do trânsito do significado (sempre lançado adiante), pela imanência dos sentidos e da percepção.

Porém, se como propus no subtítulo, com a inserção da voz no jogo poético e com a circulação (reitero: a voz se tornou capturável e reprodutível com o advento do gravador), Piva, na ordem do sentido consente lugar para Bataille, o captura nos poemas, seu nome assume valor significante, tanto que nas suas corporações e desejos, parece que Piva realiza o projeto teórico do francês, via anatomopatologia, da constituição de uma heterologia, que designaria esta "ciência" do inassimilável, do irrecuperável, dos dejetos ou restos"'.

$\mathrm{Na}$ leitura assim destas reintegrações da poética de Piva ao circuito e ao campo social, com circulação dos termos benjaminianos, o contemporâneo (na sua condição de modernidade fantasmática) poderia ser pensado não como tempo, mas como o espaço em que a experiência mediada no tempo é impossibilitada. O contemporâneo, por ser um tempo desarticulado, arrítmico, impõe-se na ordem de uma cena que é a demanda de sua configuração no lugar deste disforme. É o tempo no fundo do espelho: alucinação. A alucinação não é um dado aprés-coup, não se instaura depois do seu evento, mas como advento impõe-se enquanto demanda de um olhar que é impossível retirar da cena. Dito de outra forma: diante dos cacos da existência, viver se

\footnotetext{
${ }^{4}$ Numa tradição mais ainda próxima de Piva poderia relatar o breve ensaio de Mário de Andrade intitulado $A$ medicina dos excretos, publicado em Namoros com a medicina (1937), releitura possível de Freud - La psychopathologie de la vie quotidienne (1922), obra que consta na biblioteca de Mário.
} 
torna trabalho de imaginação, um trabalho de completar lacunas, juntar as peças, possibilitar um vislumbre imaginário (hipótese desdobrada é que não sendo possível, como propõe Lyotard, a totalidade do sujeito, a instituição estanque, na pós-modernidade, com a fragmentação destas instâncias, tudo que é possível é que se encontre e invente [invenio], por um curto espaço de tempo, um todo que permita esta circulação momentânea, reintegrando este sujeito deficitário de si a um discurso que logo também desvanece e encontra sua ruína).

Assim é que posso afirmar que Piva inverte Hegel. Se, de acordo com Derrida, Hegel cita e traduz Aristóteles, parafraseando a Metafísica e cerceando seu sentido ao escrever que aqueles que filosofam recorrendo ao mito não merecem ser tratados seriamente (DERRIDA, 1995, p. 29), Piva, ao possibilitar uma entrada pensante na esfera paranoica, implode o mito e a filosofia, o que parece existir é um campo de narrativas (em ruínas) que se tecem com o real e com a experiência. Diante disto, pergunta hegeliana, haveria em Piva uma ruína da filosofia?

A minha hipótese é que, nesse lugar alucinatório/delirante (cuja basculação depende se o situaremos no simbólico ou no imaginário) que retorna no real (efeito da foraclusão do significante-mestre), Piva inventa uma filosofia poetante radicalizada na experiência deste inassimilável, cabendo apenas ao infante poeta, enquanto soberano de uma língua esquecida, balbuciar. O poeta infans, na terminologia de Agamben, joga com a ruína da linguagem. Diante da voz, daquilo que se inscreve e da relação tensa entre sujeito, eu e corpo, na formalização desta poesia, há um desenraizamento formal, ou seja, ela não garante a forma ou a estrutura "clássica" do poema, o poema se constrói no papel ${ }^{5}$, seguindo uma não-lógica, um aprisionamento de um sopro. É dessa maneira que a proposta se marca no eixo de uma "inflexão da loucura". A inflexão é justamente o ponto de apoio de uma voz, a mudança no tom, mas também é a descida pela formação de um novo paradigma (flexão, como se concebe em termos nominais e verbais - técnica estruturalista/saussuriana por excelência, por visar a constituição do campo paradigmático das oposições na língua), na maneira como isto enoda um sentido tem-se o ponto de inflexão, o ponto em que a curva muda de direção. Lugar desta voz, noturna, e da respiração (sempre difícil ${ }^{\circ}$ ), lugar em que esta inflexão se assume como flectere, como sopro, quase num mítico ou místico (de acordo com o lugar em que as assonâncias podem guiar) assumindo a poesia como um sopro primordial, Verbo, dir-se-ia numa acepção cristã. Dessa forma, a questão da vOz assume um lugar de transcendência, toca um

\footnotetext{
${ }^{5}$ Isto é, se a primeira dimensão da poesia, neste caso, for tomada na concepção da escrita.

${ }^{6}$ Pode-se notar no áudio o valor e a tomada significante das aspirações e da força da respiração deste corpo que insiste em se marcar na cena poética.
} 
impessoal no pessoal, mônada, alma ou espírito. Verbo que nesta sua potência se desmembra em vasto circuito semântico: grito, ritmo, sussurro, canto.

Momento que exige mais um retorno a Derrida, que, em seu livro La voix et le phenomene, critica a proposta de Husserl de uma dissociação radical entre dois tipos heterogêneos de signo: o índice e a expressão. A questão é o privilégio da voz e da escritura fonética e como ela comporta esta fenomenologia. Derrida questiona o fato de que Husserl não se pergunta o que é o signo em geral, dando como exemplo a distinção entre o "être-pour"7 e o "être-à-la-place-de", questão que se liga à heterogeneidade do reenviar indicativo e expressivo. $\mathrm{Na}$ ordem da significação, no geral, toda experiência psíquica, sob a face de seus atos, mesmo aqueles que visam idealidades e necessidades, não se conhece senão os de? suas sequências indicativas.

Radicalizando o argumento, insisto que a passagem do sexual (isto é, corporal, do real que não cessa de não se inscrever) implica em certa relação com o tempo. Pode-se dizer ainda que em termos de voz o poema apresenta um corpo cativo da imagem e da palavra, o corpo como significante, como apresentação. Lugar de saída, de encontro, de passagem: corpo (também poético) posto nas incorporações das palavras. Nesses termos, a palavra também assume seu peso, o seu encontrar de um sujeito, mas há algo que escapa no registro da palavra: a experiência. A palavra pode dizer do corpo, significar como corpo, replicá-lo como imagem, porém ainda não é o corpo, como o sujeito não é o $E u$ da experiência, embora em certos momentos pareça implicá-lo. Impossível a transcendência, bem como a imanência. Nem representação absoluta da identidade $(A=B)$, nem tradução $(A \equiv B)$, mas resquício de produção de diferença $(A \neq A)$. A própria voz se realiza como disjunção, isto é, a inapropriação e a tomada "humanizada" de outros órgãos que se especializam para desempenhar e projetar a fala.

Outra questão, diante dessa sucessão de impressões, aparece: para além do aparecimento de um nome que se repete ao longo de um texto ou ao longo da história, o que acontece quando um som é reiterado?

Sendo os fones a realização do som em sua especificidade articulatória, há no campo do sensível a realização de um gozo, o qual se constitui como um prazer (hèdonen) sem remorsos, com o qual podemos gozar moderada e razoavelmente do jogo, neste caso, significante (DERRIDA, 1995, p.48). A voz então, no campo do sensível, impele o intelegível, assim descobre tanto os imitadores (a leitura derridiana do procedimento socrático) dos quais se fala, dos filósofos-políticos aos quais se fala, mas diante do qual a nossa fala resta atravessada por uma voz que vem do fundo desta caverna obscura, que configura o inacessível (a dimensão Khôra da voz) do lugar que

\footnotetext{
${ }^{7}$ Seria interessante abrir aqui a equivalência sonora entre um "être-pour" e "être-pur", com suas devidas implicações.
} 
fala e que faz falar, cuja dimensão se descola e acede ao desejo para fazer sentido, isto é, compor a possibilidade da historicidade entre o que se retém e o que se idealiza.

A oralidade também funda sua própria história. Cindindo a teoria da narrativa de Benjamin, o discurso impossibilitado de narrar (isto é, falar, elaborar um discurso sobre a experiência), vocaliza, é tomado por uma experiência na linguagem. E se, de acordo com Lacan, uma arte poética se define como uma experiência no nível do significante, uma tentativa de exacerbar, levar o significante ao seu limite, tentar encontrar o mais-além do significante. Desta maneira, diante do jogo significante, entre ruína e monumento, voz e livro, caberia inserir três pequenas questões:

(1) Qual a consistência da voz?

(2) Qual a eficácia da ruína?

(3) Qual a sobrevivência do sujeito na dimensão da voz?

Assim a pergunta, que na origem se detém aqui nesta passagem pelo sexual e textual no texto poético, cuja dimensão se dá na sedução melódica de sua estrutura, pode ser dita no quanto de sujeito e de resto podem alimentar uma história, ou ainda, o que cria o álibi de uma história. Tudo parece, assim, no palco político, das teorias e das capturas, fazer relato (o que caberia insistir se teoria literária não é um tipo singular de antropologia). Como entender, então, diante da ruína (conceito também caro aos pós-modernos, em geral, pode identificar a queda ou apagamento das instituições, da família, da tradição,etc), que Derrida, sob outra perspectiva afirme que:

[...] Eis, então, uma relação de relatos orais, uma cadeia de tradições orais, através das quais aqueles que a ela estão sujeitos se explicam como um outro, vindo de um país da escritura, explica-lhes, oralmente, porque estão destinados à oralidade (DERRIDA, 1995, p. 29).

Uma maneira de interpretar isso, no jogo de sentidos que aqui levanto, é pensar nos destinos dados às ruínas (tanto quanto à oralidade). Porém, há que prestar atenção nos sujeitos que se encenam e se cruzam nestas imagens. É sempre do mesmo sujeito (de um vazio, portanto, um sujeito fractal) que se trata ${ }^{8}$. Há muitos traços para confirmá-lo. É preciso não de síntese, mas de redução. Operar através da condensação e do deslocamento, para entrever na encenação o mínimo irredutível ${ }^{1}$. Fazer falar o poema, liberar

\footnotetext{
${ }^{8}$ Não se trata aqui de síntese, uma vez que nada permite sustentar esta identificação plena e total do eu com o sujeito.

9 Adianto aqui o ponto em que quero chegar, noutros termos freudianos/bataillanos: a obra, o excremento.
} 
esta voz que ressoa e rumoreja. Argumento de procedimento que Michel Foucault vai buscar em Brissé e em sua Gramática Lógica.

Um exemplo, tomado como paralelo do projeto de ruína da linguagem, com outro tipo de apelo (diferente do de Piva, mas ainda no seio surrealista-dadá) é aquele que dado com Tzara, a máquina não funciona mais, mas denota sua potência de fragmentação, na impossibilidade de saída do seu sistema de algaravia de "ibilivi rizididi". O gazomêtro sacerdotal de Tzara, acaba por tentar, via Cardeal Amette ${ }^{10}$ [cardinal amette], devolver o lugar desta língua(gem) que impõe um corpo híbrido que também é o corpo do prazer: "le pourquoi trans ruban de bain monsieur/bandage la bissexualité des paysages cardinal amette/au poumoin Poisson/aux doigts ribemont dessaignes GRD lubrifiant" (CANNIBALE, 1920, n. 1, p. 18), concluindo que "ça m'est complètement dada". A máquina produz a ruína.

Nesse sentido, impondo talvez uma direção alternativa de leitura, é que talvez se possa ler os banquetes estruturados pela lógica de "uma consciência participante, uma rítmica religiosa" (ANDRADE, 1978, p. 14), o que faria transparecer a afirmação de Mário de Andrade, em Aspectos da música brasileira, 1939-194111, do caráter de transformação na música:

[...] Mas a música dos primeiros jesuítas foi necessária e social, enquanto a
religião é coisa necessária e social. A crença em Deus, a esperança na Divindade,
tanto do ponto de vista espiritualista como etnográfico, não é uma superstição
inicialmente impostas pelas camadas dominantes da sociedade, não. Parte
debaixo para cima; e as massas populares dos clans são crentes por si mesmas,
crentes por natureza, por aquele necessário espírito místico próprio das
mentalidades incipientes $(1976$, p. 20$)$.

Ora, nesse turno, em que a "vanguarda brasileira" detém no seu front o grande escalão, é preciso lembrar do que se passa nas reservas (como Mário de Andrade designa o lugar, por exemplo, de Sérgio/Serge Milliet). Aqueles que ficam nas mesas paralelas do modernismo, não partilhando diretamente desta Santa Ceia, conforme o olhar de Mário de Andrade, que também o faz, a Milliet, figurar como referência de sua Obra Imatura apenas para conciliá-lo, "João" Cocteau e com o hebreu Bialik, sob a afirmação que a relevância (ou presença desses) se justificaria pelo fato, confessa, de que (os outros) poetas modernistas teriam enfraquecido singularmente sua capacidade de amar (1972, p. 213). Se os modernistas não sabem amar, a discussão à moda platônica é inacessível, a questão do "amor" só pode assim compartilhar o espaço da música n'O Banquete de Mário de Andrade. Os pontos de passagem assim são camaleônicos, porque são e não são, impondo o problema talvez como

${ }^{10}$ Cardeal Léon-Adolphe Amette, de Paris, que faleceu em 1920.

${ }^{11}$ Evolução Social da Música no Brasil (1939) / Evolução Social da Música Brasileira, 1941. 
limite à língua surrealista ou ao gesto dada, onde a ruína, o fato de que este banquete não termina, é interrompido pela contingência (ou a fatalidade), impendido assim de se descobrir o que é o doce de coco ou as frutas propostas para serem o eixo do capítulo VII, o canto dos pássaros e a aparição novamente do híbrido na figura da mulher vestida de homem (o contrário do castrato ou da representação no teatro grego e shakesperiano) do capítulo VIII, o pequeno café do capítulo IX, para chegar às despedidas, às resoluções também sobre o lugar de Janjão, no fim do banquete no capítulo X.

Como então vislumbrar o projeto poético, a ruína de si e da poesia forjada por uma tradição, por uma poesia do experienciável calcada na experiência do urbano, como é a de Piva?

O sujeito tomado pelos vazios da letra, pelos vazios da tradição, parece não saber o que fazer diante disso que se acumula nas cidades, dessa força que se acumula dentro de si e o impele à sensação do tédio implacável, mais do que a ruína das cidades e da obra de arte, o que fazer quando o que se captura é uma potencial ruína humana?

Talvez, diante do que poderíamos chamar pleonasticamente de projeto de intelectuais e de esquerda, não se possa fugir do humanismo, e este, como uma ruína simbólica, assombra-nos diante das tomadas de decisões. Com Piva, diante da dimensão da ruína, da vida e da sobrevida dos sujeitos "humanos", nos restasse perguntar, num desdobramento dos retornos e de todo projeto ético: "Onde começa a perversão e quais o sentidos que ela encontra?". O que nos levaria por tabela a tencionar, a entender as experiências de corpo posta entre o real e o virtual, imaginário e simbólico, tanto nas "novas" implicações literárias ou mesmo com os fenômenos de internet. De resto, posso afirmar, com Foucault, que a arqueologia sempre se impõe como um jogo e que diante da ruína, a dimensão ética, estética e política se impõe mediante uma falta que é sempre resultado de uma projeção ficcional, que nos obriga sempre a responder: o que podemos ainda fazer com isso?

\section{REFERÊNCIAS}

AGAMBEN, Giorgio. The end of the poem. In: The end of the poem. Translated by Daniel Heller-Roazen. Califórnia: Stanford University Press, 1996. p. 109-115.

ANDRADE, Mário de. Aspectos da música brasileira. 2. ed. São Paulo, Brasília: Livraria Martins Editora, Instituto Nacional do Livro - Ministério de Educação e Cultura, 1976.

. O Banquete. 2. ed. São Paulo: Duas Cidades, 1989.

ANDRADE, Oswald de. Do Pau-Brasil à Antropofagia e às Utopias. [Benedito Nunes (org.)]. Rio de Janeiro: Civilização Brasileira, 1978. 
BARTHES, Roland. Morte do Autor. Rumor da Língua. São Paulo: Martins Fontes, 2004.

CANNIBALE. Paris: “Au Sans Pareil”, 25 avril 1920, I.

DERRIDA, Jacques. La Grammatologie. Paris: Seuil, 1967.

. Khôra. Traduzido por. Nicia Adan Bonatti. Campinas: Papirus, 1995.

DELEUZE, Gilles. GUATTARI, Félix. Kafka: por uma literatura menor. Trad. Júlio Castañon Guimarães. Rio de Janeiro: Imago, 1977.

LACAN, Jacques. Estou falando com as paredes: conversas na Capela de Sainte-Anne. Trad. Vera Ribeiro. Rio de Janeiro: Jorge Zahar, 2011.

PIVA, Roberto. Estranhos sinais de Saturno. [Alcir Pécora (org.)]. São Paulo: Globo, 2008, v. 3.

2006, v. 2.

Mala na mão \& asas pretas. [Alcir Pécora (org.)]. São Paulo: Globo, 2005, v. 1.

Um estrangeiro na legião. [Alcir Pécora (org.)]. São Paulo: Globo,

NIETZSCHE, Friedrich. O nascimento da Tragédia: ou Helenimos e Pessimismo. Trad. J. Guinsburg. São Paulo: Companhia das Letras, 2007.

PONTE, Antonio José. Un arte de hacer ruinas y otros cuentos. México: FCE, 2005.

SEARA, Izabel Christine; NUNES, Vanessa Gonzaga; LAZZAROTTOVOLCÃO, Cristiane. Fonética e fonologia do português. Florianópolis: LLV/CCE/UFSC, 2011. 